\title{
Behavioural and physiological responses of individually housed dairy calves to change in milk feeding frequency at different ages
}

\author{
G. Scoley ${ }^{1,2 \dagger}$, A. Ashfield ${ }^{3}$, M. Romero Oiartzun ${ }^{1}$, A. Gordon ${ }^{3}$, S.J. Morrison ${ }^{1}$ \\ ${ }^{1}$ Sustainable Livestock Systems, Agri-Food and Biosciences Institute, Hillsborough, Co. Down BT26 6DR, Northern Ireland, UK \\ ${ }^{2}$ School of Biological Sciences, Queen's University Belfast BT7 1NN, Northern Ireland, UK \\ ${ }^{3}$ Agri-Food and Biosciences Institute, Newforge Lane, Belfast BT9 5PX, Northern Ireland, UK
}

Abstract

This study aimed to use a range of non-invasive monitoring technologies to investigate the behavioural and physiological responses of individually housed dairy calves to age at change in milk replacer (MR) feeding frequency. Forty-eight Holstein Friesian calves were individually penned and fed MR (625 g/d) as solids in one of three feeding regimes: (i) once-a-day feeding commencing at age $14 \mathrm{~d}$ (OAD14), (ii) once-a-day feeding commencing at age $28 d(O A D 28)$ and (iii) twice-a-day feeding (TAD). Several behavioural (automatic activity sensors), physiological (infrared [IR] thermography and heart rate variability [HRV]) and haematological indicators were used to examine calf responses. Reduction in milk feeding frequency at 14 or $28 d$ of age increased daily concentrate intakes and drinking water consumption throughout the pre-wean period. Calf lying behaviour was unaffected by reduction in milk feeding frequency; however, TAD calves recorded a significant decrease in total daily lying time during the post-wean period compared with OAD28s. There was no effect of treatment on IR eye or rectal temperature throughout the experiment; however, there was an effect of age, with IR temperature decreasing as calf age increased. OAD14 calves tended to have decreased HRV at days 14 and 16, which is suggestive of an increased stress load. The findings suggest that under high levels of animal husbandry and whilst maintaining the same amount of milk powder/d $(625 \mathrm{~g} / \mathrm{d})$, reduction in milk feeding frequency from twice to once daily at $28 \mathrm{~d}$ can occur without significant impact to behavioural, performance and physiological parameters assessed here.

Keywords

Dairy calf $\bullet$ delivery $\cdot$ feeding frequency $\bullet$ feeding plan $\bullet$ milk replacer

\section{Introduction}

Traditional calf feeding regimes have involved providing calves with restricted levels of milk or milk replacer (MR) in order to stimulate concentrate intake and thus facilitate rumen development and earlier weaning (Soberon et al., 2012). In recent years, increasing impetus has been placed on providing calves with higher levels of MR ( $\geq 8 \mathrm{~L} / \mathrm{d}$ ) (MacPherson et al., 2016), which has been positively associated with reduced age at first calving (Raeth-Knight et al., 2009) and improved first lactation milk yield (Soberon et al., 2012). Additionally, feeding higher levels of MR has been associated with reduced incidence of behaviours linked to hunger and improved calf welfare (De Paula Vieira et al., 2008; Rosenberger et al., 2017). However, conventional programmes may offer reduced rearing costs, which remains desirable for some producers (Davis \& Drackley, 1998). Furthermore, previous research has indicated that the increased consumption of solid feed in restrictively fed calves in the pre-weaning period may help reduce weaning stress and offer improved live-weight gains at weaning (Bach et al., 2013).

Despite the evident benefits to calf performance and welfare associated with increased MR feeding, in the United States, a recent survey indicated that $53 \%$ of farms provided dairy heifer calves with only 4-5 L/d of milk (USDA, 2016). Similarly, from a representative sample of 11 dairy herds in South East England, $89 \%$ indicated that dairy heifer calves were fed between 400 and $600 \mathrm{~g} / \mathrm{d}$ of MR as solids (Johnson et al., 2017). This is considerably lower than the amounts offered in the increasingly used enhanced feeding systems reported in the literature (e.g. $1.1 \mathrm{~kg} / \mathrm{d}$; Dennis et al., 2018). Additionally, $17 \%$ of calves recruited to the study were fed MR once daily 
from 3 wk of age (Johnson et al., 2017). Increasing the volume or osmolality of MR has been shown to slow abomasal emptying (Burgstaller et al., 2017), which may prolong the feeling of satiation, as such, if providing restricted levels of MR; producers may consider providing MR in one feed per day. Previous work has suggested once-daily feeding of individual or group housed calves prior to 4 wk of age as a means of reducing labour with no apparent negative effects on health or performance (Kehoe et al., 2007; Kienitz et al., 2017). However, limited research has examined the effects on measures of calf behaviour, and once-daily feeding of MR remains a contentious practice. Current guidelines indicate that calves should be fed twice daily with feedstuffs appropriate to their age and physiological development (Council Directive 2008/119/EC, 2008), which in calves under 4 wk of age are considered to be milk or MR (Van Der Burgt \& Hepple, 2013). Furthermore, research by Hulbert et al. (2011) has reported that the consolidation of two milk feeds into one at $4 \mathrm{wk}$ of age is a potential stressor. There is a need, therefore, to further examine the impact of age at implementing a once-daily feeding regime (Van Der Burgt \& Hepple, 2013).

Observational techniques have long been used to assess the effects of management practices on measures of calf behaviour; however, behavioural patterns can be inconsistent over time and their frequent use on commercial farms may be limited by cost and labour requirements (Rushen et al., 2012). In recent years, technological developments have resulted in the production of automatic monitoring systems that allow the collection of continuous, real-time data in onfarm environments (Bayne et al., 2016). Inclusion of these complementary technologies within livestock production systems can help to increase opportunities for remote collection of behavioural and physiological variables, which may help to provide a more comprehensive understanding of calf well-being (Theurer et al., 2013). Furthermore, their use within commercial operations is becoming more widespread, with a recent study indicating that $69 \%$ of dairy producers surveyed used monitoring technologies on their farm (Borchers \& Bewley, 2015). Previous research has included the use of several monitoring technologies to measure physiological and behavioural changes linked to management practices, including activity monitors (Sutherland et al., 2018), infrared (IR) thermography (Stewart et al., 2007) and heart rate (HR) monitors (Kovacs et al., 2014). As such, the objectives of this study were to:

(i) examine the impact of age at once-daily milk feeding on calf performance, behaviour and physiological responses and,

(ii) assess if behavioural and physiological responses to change in milk feeding frequency could be detected by commercially available monitoring technologies.

\section{Materials and methods}

This study was conducted at the Agri-Food and Biosciences Institute (AFBI) research farm in Hillsborough (Belfast, UK) $\left(54^{\circ} 27^{\prime} \mathrm{N} ; 06^{\circ} 04^{\prime} \mathrm{W}\right)$. All procedures and treatments within this study were conducted under a license from the Department of Health, Social Services \& Public Safety for Northern Ireland in accordance with the Animals (Scientific Procedures) Act 1986. This project was approved by the Agri-Food and Biosciences Institute Animal Welfare and Ethical Review Body.

\section{Animals}

Forty-eight Holstein Friesian calves (22 females, 26 males) born between 5 September 2014 and 14 October 2014 were allocated to the study following weighing at $<12 \mathrm{~h}$ of age, which was used as the birth weight $(41.4 \pm 4.7 \mathrm{~kg})$. All calves received $3 \mathrm{~L}$ colostrum from their own dam via oesophageal feeding tube or teated bottle within $3 \mathrm{~h}$ of birth with a second feed of $3 \mathrm{~L}$ colostrum provided $12 \mathrm{~h}$ after calving. All calves were provided with transition milk collected from the first four milkings from their own dam on days 2-3 and a mix of transition milk and MR on day 4 as detailed in Table 1. On entering the rearing accommodation at $\leq 12 \mathrm{~h}$ of age, calves were individually housed, with 12 individual straw-bedded pens $(0.9 \mathrm{~m} \times 1.8 \mathrm{~m})$ constructed inside each of four large concrete walled housing blocks $(6 \mathrm{~m} \times 6 \mathrm{~m})$ using hurdles. Calves remained in individual pens until the end of the experiment at $63 \mathrm{~d}$ of age. All housing blocks were contained within the same calf-rearing accommodation. Calves were housed in order of date of birth with four calves from each treatment within each housing block. Calves had visual contact with all conspecifics within each housing block and nose-to-nose contact with calves in neighbouring individual pens. Calves were vaccinated with Bovilis Bovipast RSP (MSD Animal Health, Milton Keynes, UK) at 2 wk of age with a secondary dose given 4 wk later at which point calves were vaccinated with Bovilis IBR Marker Live (MSD Animal Health, Milton Keynes, UK).

\section{Treatments and experimental design}

The study commenced when calves reached $5 \mathrm{~d}$ of age from which point they were offered MR according to one of three feeding regimes: (i) once-a-day feeding commencing at age 14 d (OAD14), (ii) once-a-day feeding commencing at age $28 \mathrm{~d}$ (OAD28) and (iii) twice-a-day feeding (TAD). It was decided to reduce MR feeding frequency at these time points so as to reflect the age at which it has previously been indicated as a stressor (OAD28; Hulbert et al., 2011) and an age at which it has previously been reported as occurring on farm (OAD14; Kehoe et al., 2007). During the experimental period, the liquid 
Table 1: Feeding plan for colostrum/TM and milk replacer from birth to $55 \mathrm{~d}$ of age

\begin{tabular}{|c|c|c|c|c|c|c|c|c|c|}
\hline \multirow[t]{2}{*}{ Day } & \multicolumn{3}{|c|}{ OAD14 ${ }^{1}$} & \multicolumn{3}{|c|}{ OAD28 $^{1}$} & \multicolumn{3}{|c|}{ TAD $^{1}$} \\
\hline & $\begin{array}{c}\text { No. of } \\
\text { feeds/d }\end{array}$ & $\begin{array}{c}\text { Total } \\
\text { volume }(\mathrm{L})^{2}\end{array}$ & $\begin{array}{c}\text { Total } \\
\text { solids }^{3}\end{array}$ & $\begin{array}{c}\text { No. of } \\
\text { feeds } / d\end{array}$ & $\begin{array}{c}\text { Total } \\
\text { volume }(\mathrm{L})^{2}\end{array}$ & $\begin{array}{c}\text { Total } \\
\text { solids }^{3}\end{array}$ & $\begin{array}{c}\text { No. of } \\
\text { feeds/d }\end{array}$ & $\begin{array}{c}\text { Total } \\
\text { volume }(\mathrm{L})^{2}\end{array}$ & $\begin{array}{c}\text { Total } \\
\text { solids }^{3}\end{array}$ \\
\hline 0 & 1 & 3 & - & 1 & 3 & - & 1 & 3 & - \\
\hline 0.5 & 1 & 3 & - & 1 & 3 & - & 1 & 3 & - \\
\hline $1^{4}$ & 2 & 4 & - & 2 & 4 & - & 2 & 4 & - \\
\hline $2-3^{5}$ & 2 & 4 & - & 2 & 4 & - & 2 & 4 & - \\
\hline $4^{6}$ & 2 & 4 & 250 & 2 & 4 & 250 & 2 & 4 & 250 \\
\hline $5-7$ & 2 & 4 & 500 & 2 & 4 & 500 & 2 & 4 & 500 \\
\hline $8-13$ & 2 & 5 & 625 & 2 & 5 & 625 & 2 & 5 & 625 \\
\hline $14-27$ & 1 & 3.5 & 625 & 2 & 5 & 625 & 2 & 5 & 625 \\
\hline $28-55$ & 1 & 3.5 & 625 & 1 & 3.5 & 625 & 2 & 5 & 625 \\
\hline
\end{tabular}

${ }^{1}$ Dietary treatment: OAD14 = once-a-day feeding milk replacer diet from $14 \mathrm{~d}$ of age, OAD28 = once-a-day feeding milk replacer diet from $28 \mathrm{~d}$ of age and TAD = twice-a-day feeding milk replacer diet.

${ }^{2}$ Total daily volume of colostrum/TM or reconstituted milk replacer provided in litres (L).

${ }^{3}$ Total solids of milk replacer powder presented in grams $(\mathrm{g})$ on an as fed fresh basis.

${ }^{4}$ Colostrum from own dam.

${ }^{5} \mathrm{TM}$ from own dam.

${ }^{6}$ Mix of half TM and half milk replacer with each feed consisting of $1 \mathrm{LTM}$ and $1 \mathrm{~L}$ milk replacer mixed together.

$\mathrm{TM}=$ transition milk.

diet consisted of a whey-based MR (Volac International Ltd, Hertfordshire, UK). Milk replacer was diluted at a rate of $17.8 \%$ and $12.5 \%$, respectively, for calves fed once and twice per day (Table 1). Starter concentrate and fresh drinking water were provided on an ad libitum basis from $5 \mathrm{~d}$ of age. Calves were balanced across treatments for sex and birth weight. All calves were abruptly weaned at $56 \mathrm{~d}$ of age, and the study was completed when calves reached $63 \mathrm{~d}$ of age.

\section{Data collection}

\section{Calf performance}

Individual daily concentrate intake was recorded between 5 and $62 \mathrm{~d}$ of age. Individual drinking water intake was recorded $5 \mathrm{~d} / \mathrm{wk}$ between 5 and $62 \mathrm{~d}$ of age. Intakes were calculated by subtracting the refused feed from the amount offered on a daily basis. Live weights were recorded weekly according to individual calf age between 7 and $63 \mathrm{~d}$ of age. Weighing was conducted using a calibrated mobile weighbridge (Tru-Test Eziweigh 5, Auckland, New Zealand) and occurred between 2 and $4 \mathrm{~h}$ post ante meridiem (AM) MR feed.

\section{Feed nutrient composition}

Samples of MR, starter concentrate and fresh straw bedding were collected on a daily basis and bulked for each 2-wk period throughout the experiment. MR, concentrate and straw were analysed for dry matter content, with dried samples then analysed for nitrogen content using methods as previously described by Steen (1989). Concentration of acid detergent fibre, neutral detergent fibre and ash were analysed based on the method described by Cushnahan \& Gordon (1995). Gross energy content of starter concentrate and straw was determined using the method described by Porter (1992). Chemical composition of feedstuffs is presented in Table 2 .

\section{Blood sampling}

Single-point blood samples were taken via jugular venipuncture using $10 \mathrm{~mL}$ clot-activated serum separation Vacutainer tubes (BD, Plymouth, UK) at days $-7,-3,0,+3$ and +7 relative to the introduction of the imposed nutritional

Table 2: Chemical composition of milk replacer, concentrate and straw used as bedding

\begin{tabular}{lccc}
\hline Variable & Milk replacer & Concentrate & Straw \\
\hline DM (g/kg fresh) & 948 & 954 & 932 \\
Nitrogen (g/kg DM) & 38.1 & 31.0 & 5.9 \\
NDF (g/kg DM) & - & 305.4 & 859.6 \\
ADF (g/kg DM) & - & 149.2 & 525.0 \\
Ash (g/kg DM) & 66.2 & 75.9 & 49.7 \\
Ether extract (g/kg DM) & 186.7 & 40.8 & 11.9 \\
Gross energy (MJ/kg DM) & 21.3 & 18.0 & 18.6 \\
\hline
\end{tabular}

$\mathrm{DM}=$ dry matter, NDF $=$ neutral detergent fibre, $\mathrm{ADF}=$ acid detergent fibre. 
stressors, being reduction of milk feeding frequency to once daily at 14 or $28 \mathrm{~d}$ of age for OAD14 or OAD28 treatment, respectively, and abrupt weaning of all calves at $56 \mathrm{~d}$ of age (Figure 1). Samples taken between days 7 and 21 were classified as Period 1, days 21 and 35 as Period 2 and days 49 and 63 as Period 3. Samples were taken 3-4 h post AM MR feed (Kehoe et al., 2007) to allow for analysis of nonesterified fatty acids (NEFA), urea, $\beta$-hydroxybutyrate (BHBA) and haptoglobin $(\mathrm{Hp})$. A second sample taken on these days using fluoride oxalate-coated vacutainers (BD, Plymouth, UK) was used for glucose analysis. Blood tubes were centrifuged at 3,000 rpm for $15 \mathrm{~min}$ (Eppendorf 5810R, Eppendorf UK, Stevenage, UK) after which the supernatant was decanted and stored at $-20^{\circ} \mathrm{C}$ until analysis by enzymatic assay (Audit Diagnostics Sapphire 800 automated dry chemistry analyser, Audit Diagnostics, Cork, Ireland).

\section{Thermal imaging}

Thermal imaging was carried out $2 \mathrm{~h}$ post AM feed $5 \mathrm{~d} / \mathrm{wk}$ between days 7 and 21 (Period 1), 21 and 35 (Period 2) and 49 and 62 (Period 3). Images of each individual calf were taken by a trained operator using a calibrated FLIR E8 camera (FLIR Systems UK, Kent, UK) and were of the right eye (plus a $1 \mathrm{~cm}$ area surrounding the eye) and the anus (plus a $1 \mathrm{~cm}$ area surrounding the anus). Images were taken in duplicate at a consistent distance $(\sim 0.5 \mathrm{~m})$ and angle $\left(\sim 90^{\circ}\right)$ whilst the calf was standing. For purposes of standardisation, images were taken within the individual pens prior to introduction of any potential stressors such as weighing or blood sampling. Calves quickly became habituated to the process, allowing for very limited handling from the camera operator. Images were processed using FLIR Tools ${ }^{\circledast}$ software (FLIR Systems UK, Kent, UK) by the same operator with maximum, average and minimum temperatures extracted. Ambient temperature $\left({ }^{\circ} \mathrm{C}\right)$ and relative humidity (\%) were recorded using a calibrated EBI 20-TH data logger (ebro Electronic, Ingolstadt, Germany) inside the calf house, and an average of values obtained during the corresponding time period was entered into the software programme during image processing to allow for atmospheric changes during the sampling period.

\section{Lying behaviour}

IceRobotics ${ }^{\circledast}$ IceQube ${ }^{\circledR}$ automatic activity sensors (IceRobotics Ltd., Edinburgh, Scotland, UK) were fitted to the same six calves per treatment, balanced for sex and birth weight, over three time periods when calves were 10-19 (Period 1), 24-33 (Period 2) and 54-62 (Period 3) d old. Sensors were fitted to the lateral side of the right rear leg in agreement with current best practice (Budzynska \& Weary, 2008; Bonk et al., 2013). An optimal correction filter that removed sensor recordings lasting $\leq 8 \mathrm{~s}$ was applied to data prior to analysis (Finney et al., 2018).

\section{Herat rate monitors}

Eleven, nine and 10 calves from treatments OAD14, OAD28 and $T A D$, respectively, were fitted with a Polar Equine RS800CX Science (Polar Electro UK Ltd, Heathcote Way, Warwick, UK) heart monitor over three time periods of age: 12-16 (Period 1), 26-30 (Period 2) and 54-58 (Period 3) d. These periods were chosen to reflect times when a nutritional stressor was imposed: MR feeding frequency reduction at 14 or $28 \mathrm{~d}$ of age for OAD14 and OAD28 calves, respectively, and abrupt weaning of all calves at $56 \mathrm{~d}$ of age. Monitors were fitted 1-2 $\mathrm{h}$ post AM MR feed on each sampling day and remained on calves for $2-3 \mathrm{~h}$ to allow data capture during the period when calves were undisturbed and most likely to be resting. Electrode gel (Spectra 360 Electrode Gel, Parker Laboratories Inc., Fairfield, NJ, USA) was applied to ensure contact between the calf and monitor (Clapp et al., 2014).

Recordings were processed using both the Artifact and Polar software (Kaufmann et al., 2011). The time period from which data were selected was between the recommended 5-10 min duration (Anonymous, 1996) with video recordings of housing blocks used to verify that calves were undisturbed during the
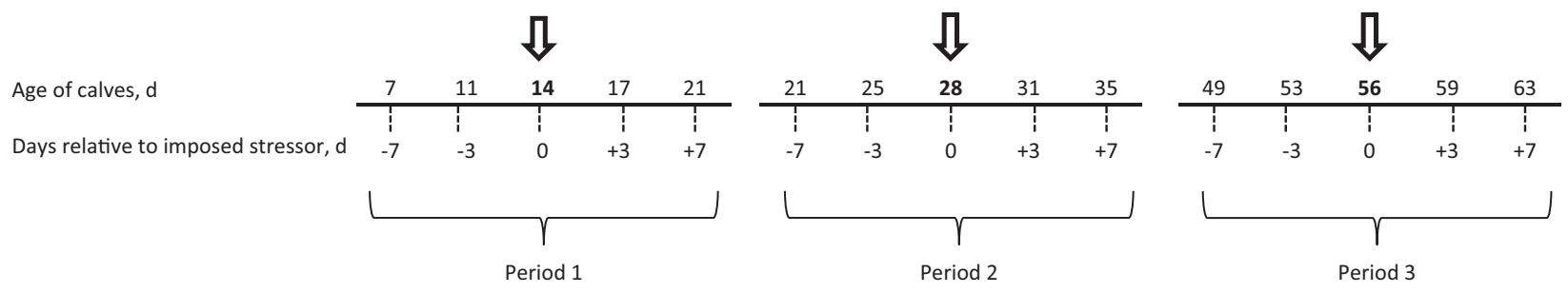

Figure 1. Timeline of haematological sampling throughout Periods 1-3. Arrow indicates days that nutritional stressors were imposed; commencement of once-daily MR feeding at days 14 and 28 for OAD14 and OAD28 calves, respectively, and abrupt weaning of all calves at day 56. MR = milk replacer, OAD14 = once-a-day feeding milk replacer diet from $14 \mathrm{~d}$ of age, OAD28 = once-a-day feeding milk replacer diet from $28 \mathrm{~d}$ of age. 
selected period of time. Preliminary error correction of the data set was conducted using the Polar software settings as described by Clapp et al. (2014) with any data set requiring more than a 5\% error correction rejected (Stewart et al., 2009). Following error correction, the data set was further processed using Artiifact software with resultant root mean squares of successive differences (RMSSD) of time between each heartbeat and HR used in the analysis (von Borell et al., 2007).

\section{Statistical analysis}

All data were analysed using GenStat $^{\circledR}$ (version 16.2; VSN International Ltd, Hemel Hempsted, UK). All statistical models included birth weight as a covariate and housing block and calf as random terms unless otherwise stated. A probability of $P<0.05$ was selected as the level of significance, and where data was significant, it was subjected to Fisher's protected least significant difference test.

\section{Calf performance}

Calf live weight, daily concentrate intake and daily drinking and total water intake were fitted to a repeated measures residual maximum likelihood (REML) estimation model with effects of sex, age, treatment and the interaction of treatment $x$ age included. Concentrate and water intakes were also split into three time periods: days 5-13, days 14-27 and days 28-55 to reflect periods when reduction in milk feeding frequency occurred and analysed using the aforementioned repeated measures REML model. Live-weight gain, feed conversion efficiency (FCE), total concentrate intake, total drinking water intake and average rectal temperature were analysed using a mixed-effects model with fixed effects of sex and treatment.

Haematological, physiological and behavioural measures Concentration of blood metabolites, Hp, eye temperature, lying behaviour, HR and heart rate variability (HRV) data were analysed individually by period using the REML model as previously described. Within the blood metabolite and $\mathrm{Hp}$ analyses, the day -7 result of each period was included as a covariate with treatment means presented for each time period. Within the eye temperature, HR and standing/ lying behaviour data, a baseline value was derived by averaging the pre-day 0 data for each period and used as a covariate.

\section{Temperature methods}

Daily IR eye, IR rectal and manual rectal temperatures over the entire experimental period were fitted to a repeated measures power city block distance model with calf treatment, method, age and the interactions fitted as fixed effects and sex as a covariate. Data were then analysed by individual period using the same model. Correlation between each of the three temperature methods was analysed by linear regression using the predicted means obtained through the repeated measures analysis.

\section{Results}

\section{Intakes}

Starter concentrate intake tended to be increased in OAD14 calves between days 28 and 55 when compared with TAD calves (Table 3; $P=0.073$ ). Both OAD14 and OAD28 calves tended to have increased daily concentrate consumption between days 5 and 55 compared with TAD calves (Figure 2A and Table 3; $P=0.052)$. There was no effect of treatment on daily concentrate intake or total concentrate intake in the period immediately post weaning (Table 3). Consumption of drinking water tended to be increased in OAD14 calves between days 14 and 27 (Table 3; $P=0.051$ ). Both OAD14 and OAD28 calves consumed more drinking water on a daily basis than TAD calves between days 28 and 55 (Table 3; $P<0.001$ ) and when analysed over days 5-55 (Figure 2B and Table 3). Total water consumption, the cumulative total of drinking water plus water used in reconstituted milk powder, was lower in OAD14 calves between days 14 and 27 (Table 3; $P<0.001)$ and in OAD14 and OAD28 calves between days 28 and 55 (Table $3 ; P<0.001$ ). When analysed over days $5-55$, daily total water intake was increased by 287 and $641 \mathrm{~mL}$ in TAD calves when compared with that in OAD28 and OAD14 calves, respectively (Figure $2 \mathrm{C}$ and Table $3 ; P<0.001$ ). There were no treatment differences in drinking water consumption in the post-wean period (Table 3).

\section{Live weight, live-weight gain and FCE}

Live weight at weaning (day 56), end of experiment (day 63) and live-weight gains throughout the experimental period for the three treatments are reported in Table 4. Live weight and live-weight gain were unaffected by treatment throughout the experimental period. FCE (kg gain/kg dry matter intake [DMI]) was comparable across treatments between days 5 and 55 (Table 4). There was a tendency for improved FCE in OAD28 calves between days 14 and 27 (Table 4; $P=0.055$ ); however, this did not persist between days 28 and 55 when FCE tended to be improved in TAD calves when compared with OAD14 calves (Table $4 ; P=0.076$ ).

\section{Haematological variables}

In Period 1, there were no effects of treatment, sampling day or treatment $\times$ sampling day on the concentration of blood metabolite variables (Table 5). However, average concentration of $\mathrm{Hp}$ increased from 0.30 to $0.40 \mathrm{~g} / \mathrm{L}$ between days 14 and 21 across all treatments $(P<0.001)$. 
Table 3: Average daily intake of concentrate (DM basis), drinking water and total water

\begin{tabular}{|c|c|c|c|c|c|c|}
\hline \multirow[t]{2}{*}{ Variable } & \multicolumn{3}{|c|}{ Dietary treatment $(D)$} & \multirow[t]{2}{*}{ SED } & \multicolumn{2}{|c|}{$P$-value } \\
\hline & OAD14 1 & OAD28 1 & TAD $^{1}$ & & $D$ & $D \times T^{2}$ \\
\hline \multicolumn{7}{|c|}{ Concentrate (g DM/d) } \\
\hline d5-55 & 675 & 647 & 542 & 48.9 & 0.052 & 0.710 \\
\hline d5-13 & 108 & 102 & 90 & 24.2 & 0.767 & 0.607 \\
\hline d14-27 & 368 & 319 & 261 & 49.7 & 0.107 & 0.494 \\
\hline d28-55 & 1,013 & 987 & 864 & 66.8 & 0.073 & 0.865 \\
\hline d56-62 & 2,245 & 2,223 & 2,198 & 59.7 & 0.760 & 0.990 \\
\hline \multicolumn{7}{|c|}{ Drinking water ${ }^{3}(\mathrm{~g} / \mathrm{d})$} \\
\hline d5-55 & $1,578^{b}$ & $1,520^{\mathrm{b}}$ & $980^{\mathrm{a}}$ & 115.4 & $<0.001$ & 0.001 \\
\hline d5-13 & 531 & 642 & 581 & 158.6 & 0.503 & 0.622 \\
\hline d14-27 & 1,023 & 577 & 673 & 178.9 & 0.051 & 0.924 \\
\hline d28-55 & $2,197^{b}$ & $2,272^{b}$ & $1,262^{a}$ & 169.3 & $<0.001$ & 0.095 \\
\hline d56-62 & 6,350 & 6,502 & 6,121 & 342.3 & 0.570 & 0.750 \\
\hline \multicolumn{7}{|c|}{ Total water $(\mathrm{g} / \mathrm{d})$} \\
\hline d5-55 & $4,666^{a}$ & $5,020^{\mathrm{b}}$ & $5,307^{c}$ & 115.4 & $<0.001$ & $<0.001$ \\
\hline d14-27 & $3,898^{a}$ & $4,952^{b}$ & $5,048^{b}$ & 178.9 & $<0.001$ & 0.924 \\
\hline d28-55 & $5,072^{\mathrm{a}}$ & $5,147^{a}$ & $5,637^{b}$ & 169.3 & $<0.001$ & 0.095 \\
\hline
\end{tabular}

${ }^{\mathrm{a}-\mathrm{c} R}$ Row values with different superscripts differ significantly.

${ }^{1}$ Dietary treatment $(D)$ : OAD14 = once-a-day feeding milk replacer diet from $14 \mathrm{~d}$ of age, OAD28 = once-a-day feeding milk replacer diet from $28 \mathrm{~d}$ of age, TAD = twice-a-day feeding milk replacer diet.

${ }^{2} T$ = sampling day and $D \times T=$ dietary treatment $\times$ sampling day interaction.

${ }^{3}$ Drinking water intake based on measurements taken on 5 consecutive days per week.

${ }^{4}$ Total water is the cumulative total of drinking water and water used to reconstitute milk powder.

$\mathrm{DM}=$ dry matter, SED = standard error of the difference.

In Period 2, concentration of BHBA increased from 0.12 to $0.17 \mathrm{mmol} / \mathrm{L}$ between days 28 and 35 across all treatments $(P<0.001)$. During the same period, average glucose concentration was lower in TAD calves than in OAD14 and OAD28 calves (Table $5 ; P=0.020$ ) and average NEFA concentration was lower in OAD14 calves than in TAD and OAD28 calves (Table 5; $P=0.009$ ). There were no effects of treatment, sampling day or treatment $\times$ sampling day on concentration of urea or $\mathrm{Hp}$ throughout Period 2 (Table 5).

In Period 3, BHBA concentration peaked on day 59 with an average value of $0.41 \mathrm{mmol} / \mathrm{L}$ across all treatments $(P=$ $0.006)$. In the same period, urea concentration was lower on day 56 (day of abrupt weaning) when compared with days 59 and $63(P<0.001)$. There were no effects of treatment, sampling day or treatment $\times$ sampling day on concentration of NEFA, glucose or Hp throughout Period 3 (Table 5).

\section{Thermal imaging}

There was no effect of treatment or treatment $\times$ age on maximum daily IR eye temperature, IR rectal temperature or manual rectal temperature throughout the three experimental periods. However, during Period 3, there was an effect of age, with maximum eye temperature decreasing as calves aged (Figure 3; $P<0.001$ ). A significant interaction between age and method of taking temperature was found over the course of the experimental period $(P<0.001)$.

There was no correlation between IR temperature of the eye and manual rectal temperature throughout Period 1 or 2; when all three time periods were combined, however, there was a strong positive correlation between the two methods in Period $3\left(R^{2}=0.61 ; P<0.001\right)$. Manual rectal temperature was consistently higher than IR eye temperature across all time periods $(P<0.001)$. Correlation between IR rectal temperature and manual rectal temperature increased throughout the three experimental periods, with a moderate correlation found between the two methods in Period $3\left(R^{2}\right.$ $=0.57 ; P=0.001)$ and a low correlation found when all experimental periods were combined $\left(R^{2}=0.16 ; P=0.004\right)$.

\section{Lying behaviour}

There were no effects of treatment, age or treatment $x$ age on number of daily lying bouts, lying bout duration or total daily 

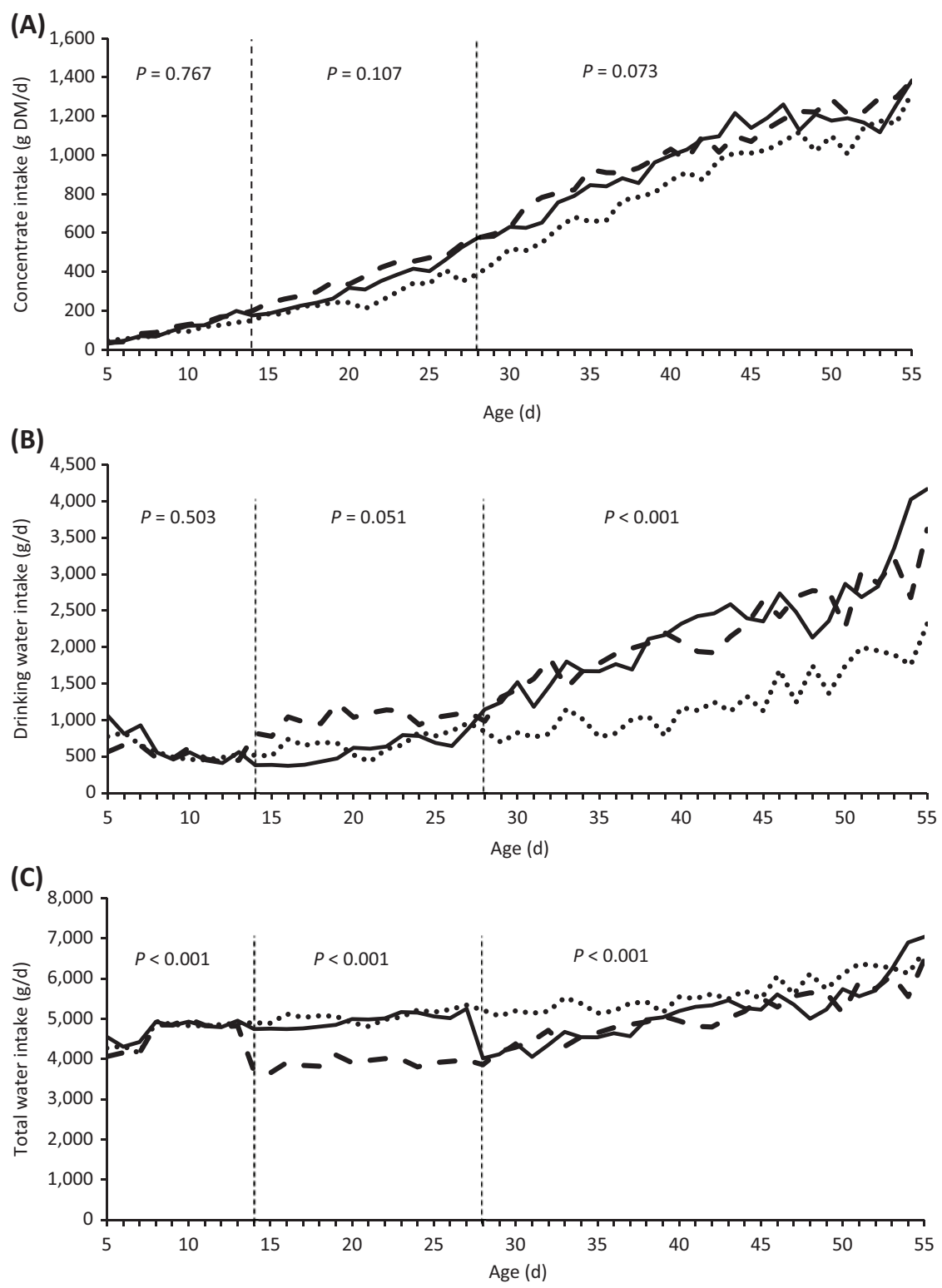

Figure 2. Daily concentrate (A), drinking water $(B)$, and total water $(C)$ intake of calves throughout the pre-wean period. OAD14 $(--)=$ oncea-day feeding milk replacer diet from $14 \mathrm{~d}$ of age; OAD28 $(-)=$ once-a-day feeding milk replacer diet from $28 \mathrm{~d}$ of age; TAD ( $\cdots \cdots.)=$ twice-aday feeding milk replacer diet.

lying time throughout Periods 1 and 2 with calves across all treatments spending approximately 1,122 min per day lying (Table 6). During Period 3, lying time was an average of 48 min less in TAD calves than in OAD28 calves (Table 6; $P=0.043)$.

There was no difference in hourly lying behaviour between treatments following reduction in MR feeding frequency at $14 \mathrm{~d}$ of age (Figure $4 ; P=0.183$ ). Hourly lying time tended to be increased in OAD28 calves following reduction in MR feeding frequency at $28 \mathrm{~d}$ of age (Figure $4 ; P=0.065$ ); however, this difference was minimal, representing an increase of only 1.7 and $1.4 \mathrm{~min}$ when compared with that in OAD14 and TAD calves, respectively. There was no difference in hourly lying time following abrupt weaning at $56 \mathrm{~d}$ of age (Figure $4 ; P=0.325$ ). 
Table 4: Live weight, live-weight gain and FCE of calves

\begin{tabular}{|c|c|c|c|c|c|c|}
\hline \multirow[t]{2}{*}{ Variable } & \multicolumn{3}{|c|}{ Dietary treatment $(D)$} & \multirow[t]{2}{*}{ SED } & \multicolumn{2}{|c|}{$P$-value } \\
\hline & OAD14 1 & OAD28 ${ }^{1}$ & TAD1 & & $D$ & $D \times T^{2}$ \\
\hline \multicolumn{7}{|c|}{ Live weight (kg) } \\
\hline d28 & 56.6 & 55.9 & 54.7 & 1.25 & 0.73 & 0.24 \\
\hline d56 & 79.3 & 78.4 & 76.6 & & & \\
\hline d63 & 85.9 & 84.7 & 83.9 & & & \\
\hline \multicolumn{7}{|c|}{ Live-weight gain $(\mathrm{kg} / \mathrm{d})$} \\
\hline $\mathrm{d} 0-28$ & 0.55 & 0.52 & 0.49 & 0.039 & 0.25 & - \\
\hline $\mathrm{d} 0-56$ & 0.71 & 0.71 & 0.66 & 0.028 & 0.14 & - \\
\hline do-63 & 0.71 & 0.69 & 0.67 & 0.031 & 0.59 & - \\
\hline d28-56 & 0.83 & 0.82 & 0.81 & 0.033 & 0.78 & - \\
\hline d56-63 & 0.95 & 0.90 & 1.03 & 0.114 & 0.55 & - \\
\hline \multicolumn{7}{|c|}{$\mathrm{FCE}^{3}$ (kg gain/kg DMI) } \\
\hline d5-55 & 0.59 & 0.59 & 0.60 & 0.014 & 0.562 & - \\
\hline d14-27 & 0.64 & 0.73 & 0.63 & 0.044 & 0.055 & - \\
\hline d28-55 & 0.50 & 0.51 & 0.55 & 0.021 & 0.076 & - \\
\hline
\end{tabular}

${ }^{1}$ Dietary treatment $(D)$ : OAD14 = once-a-day feeding milk replacer diet from $14 \mathrm{~d}$ of age, OAD28 = once-a-day feeding milk replacer diet from $28 \mathrm{~d}$ of age, $T A D=$ twice-a-day feeding milk replacer diet.

${ }^{2} T$ = sampling day, $D \times T=$ dietary treatment $\times$ sampling day interaction.

${ }^{3} \mathrm{FCE}=$ feed conversion efficiency calculated in terms of $\mathrm{kg}$ gain $/ \mathrm{kg} \mathrm{DMI}$.

$\mathrm{DMI}=$ dry matter intake, SED $=$ standard error of the difference.

Table 5: Effects of age at commencement of once-daily milk feeding and weaning on the concentration of blood metabolites and serum

\begin{tabular}{|c|c|c|c|c|c|c|c|c|}
\hline \multirow[t]{2}{*}{ Period $^{\mp}$} & \multirow[t]{2}{*}{ Variable } & \multicolumn{3}{|c|}{ Dietary treatment $(D)$} & \multirow[t]{2}{*}{ SED } & \multicolumn{3}{|c|}{$P$-value } \\
\hline & & OAD14 $^{1}$ & OAD28 ${ }^{1}$ & TAD $^{1}$ & & $D^{2}$ & $T^{2}$ & $D \times T^{2}$ \\
\hline \multirow[t]{5}{*}{1} & $\mathrm{BHBA}^{4}(\mathrm{mmol} / \mathrm{L})$ & 0.10 & 0.10 & 0.08 & 0.007 & 0.177 & 0.149 & 0.907 \\
\hline & Glucose $(\mathrm{mmol} / \mathrm{L})$ & 6.39 & 6.32 & 6.15 & 0.184 & 0.461 & 0.076 & 0.846 \\
\hline & $\mathrm{NEFA}^{5}(\mathrm{Meq} / \mathrm{L})$ & 0.28 & 0.26 & 0.26 & 0.015 & 0.153 & 0.228 & 0.617 \\
\hline & Urea (mmol/L) & 2.22 & 2.11 & 2.25 & 0.101 & 0.279 & 0.543 & 0.186 \\
\hline & $\mathrm{Hp}^{6}(\mathrm{~g} / \mathrm{L})$ & 0.35 & 0.36 & 0.33 & 0.022 & 0.497 & $<0.001$ & 0.386 \\
\hline \multirow[t]{5}{*}{2} & $\mathrm{BHBA}^{4}(\mathrm{mmol} / \mathrm{L})$ & 0.14 & 0.15 & 0.15 & 0.019 & 0.635 & $<0.001$ & 0.230 \\
\hline & Glucose (mmol/L) & $6.25^{\mathrm{b}}$ & $6.43^{b}$ & $5.88^{\mathrm{a}}$ & 0.184 & 0.020 & 0.433 & 0.132 \\
\hline & $\operatorname{NEFA}^{5}(\mathrm{Meq} / \mathrm{L})$ & $0.29^{\mathrm{a}}$ & $0.34^{b}$ & $0.33^{b}$ & 0.016 & 0.009 & 0.813 & 0.962 \\
\hline & Urea (mmol/L) & 2.28 & 2.35 & 2.25 & 0.092 & 0.421 & 0.549 & 0.819 \\
\hline & $\mathrm{Hp}^{6}(\mathrm{~g} / \mathrm{L})$ & 0.39 & 0.35 & 0.35 & 0.024 & 0.054 & 0.424 & 0.517 \\
\hline \multirow[t]{5}{*}{3} & $\mathrm{BHBA}(\mathrm{mmol} / \mathrm{L})$ & 0.37 & 0.38 & 0.31 & 0.041 & 0.081 & 0.006 & 0.776 \\
\hline & Glucose (mmol/L) & 5.04 & 4.96 & 4.95 & 0.150 & 0.840 & 0.910 & 0.272 \\
\hline & NEFA (Meq/L) & 0.23 & 0.23 & 0.22 & 0.014 & 0.767 & 0.892 & 0.785 \\
\hline & Urea $(\mathrm{mmol} / \mathrm{L})$ & 2.72 & 2.74 & 2.89 & 0.140 & 0.615 & $<0.001$ & 0.044 \\
\hline & $\mathrm{Hp}(\mathrm{g} / \mathrm{L})$ & 0.44 & 0.38 & 0.42 & 0.034 & 0.176 & 0.710 & 0.612 \\
\hline
\end{tabular}

FPeriod $1=7-21 \mathrm{~d}$ of age, Period $2=21-35 \mathrm{~d}$ of age, Period $3=49-63 \mathrm{~d}$ of age.

${ }^{1}$ Dietary treatment $(D)$ : OAD14 = once-a-day feeding milk replacer diet from $14 \mathrm{~d}$ of age, OAD28 = once-a-day feeding milk replacer diet from $28 \mathrm{~d}$ of age, TAD = twice-a-day feeding milk replacer diet.

${ }^{2} D=$ treatment, ${ }^{2} T=$ sampling day, ${ }^{3} D \times T=$ dietary treatment $\times$ sampling day interaction.

${ }^{a-b}$ Row values with different superscripts differ significantly.

$\mathrm{BHBA}=\beta$-hydroxybutyrate, NEFA $=$ non-esterified fatty acids, $\mathrm{Hp}=$ haptoglobin, $\mathrm{SED}=$ standard error of the difference. 


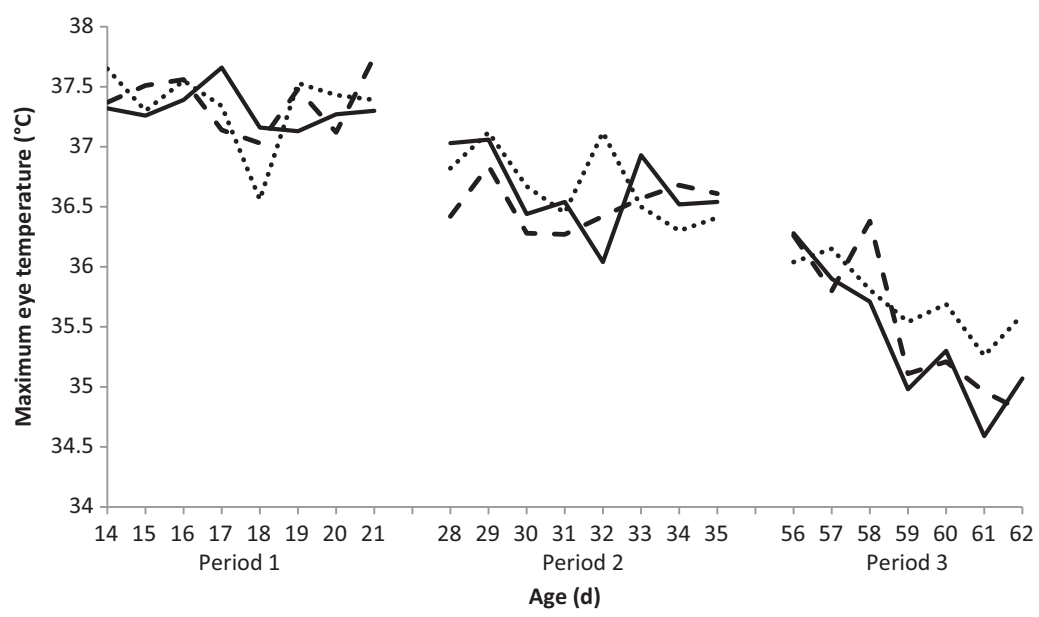

Figure 3. Maximum infrared eye temperature of calves over the milk step-down and weaning periods. OAD14 (- -) = once-a-day feeding milk replacer diet from $14 \mathrm{~d}$ of age, OAD28 $(-)=$ once-a-day feeding milk replacer diet from $28 \mathrm{~d}$ of age and TAD $(\cdots \cdots)=$ twice-a-day feeding milk replacer diet.

Table 6: Daily number of lying bouts, average lying bout duration $(\mathrm{min})$ and total lying time $(\mathrm{min})$ of calves throughout periods $1-3$

\begin{tabular}{|c|c|c|c|c|c|c|c|c|}
\hline \multirow[t]{2}{*}{ Period $^{\mp}$} & \multirow[t]{2}{*}{ Variable } & \multicolumn{3}{|c|}{ Dietary treatment $(D)$} & \multirow[b]{2}{*}{ SED } & \multicolumn{3}{|c|}{$P$-value } \\
\hline & & OAD14 1 & OAD28 1 & TAD $^{1}$ & & $D$ & $T^{2}$ & $D \times T^{2}$ \\
\hline \multirow[t]{3}{*}{1} & Number of daily lying bouts & 18.2 & 17.5 & 19.0 & 2.22 & 0.489 & 0.799 & 0.142 \\
\hline & Average daily lying bout duration (min) & 60.6 & 68.6 & 63.8 & 5.74 & 0.478 & 0.343 & 0.439 \\
\hline & Daily total lying time (min) & 1,113 & 1,133 & 1,126 & 20.2 & 0.605 & 0.662 & 0.749 \\
\hline \multirow[t]{3}{*}{2} & Number of daily lying bouts & 18.1 & 19.3 & 19.6 & 1.75 & 0.763 & 0.555 & 0.338 \\
\hline & Average daily lying bout duration (min) & 60.8 & 59.9 & 60.7 & 5.32 & 0.960 & 0.559 & 0.285 \\
\hline & Daily total lying time (min) & 1,119 & 1,128 & 1,111 & 19.8 & 0.711 & 0.627 & 0.472 \\
\hline \multirow[t]{3}{*}{3} & Number of daily lying bouts & 22.8 & 21.0 & 20.6 & 1.25 & 0.262 & 0.067 & 0.582 \\
\hline & Average daily lying bout duration (min) & 49.8 & 54.2 & 52.5 & 3.09 & 0.376 & 0.133 & 0.571 \\
\hline & Daily total lying time ( $\min )$ & $1,087^{a, b}$ & $1,105^{b}$ & $1,057^{a}$ & 20.1 & 0.043 & 0.702 & 0.928 \\
\hline
\end{tabular}

${ }^{\mp}$ Period $1=10-19 \mathrm{~d}$ of age, Period $2=24-33 \mathrm{~d}$ of age, Period $3=54-62 \mathrm{~d}$ of age.

${ }^{1}$ Dietary treatment $(D)$ : OAD14 = once-a-day feeding milk replacer diet from $14 \mathrm{~d}$ of age, OAD28 = once-a-day feeding milk replacer diet from $28 \mathrm{~d}$ of age, TAD = twice-a-day feeding milk replacer diet.

${ }^{2} T$ = sampling day, $D \times T=$ dietary treatment $\times$ sampling day interaction.

${ }^{a-b}$ Row values with different superscripts differ significantly.

SED $=$ standard error of the difference.

\section{Heart rate and heart rate variability}

There was no difference in HR (bpm) between treatments following reduction in milk feeding frequency at 14 or $28 \mathrm{~d}$ of age or following abrupt weaning at $56 \mathrm{~d}$ of age (Table 7). During Period 1, a tendency for lower RMSSD (ms), a measurement based on the time between each heartbeat and linked to vagal tone, was found in OAD14 calves on days 14 and 16 when compared with that in OAD28 calves (Table 7; $P=0.061$ ). There were no effects of treatment, sampling day or treatment $\times$ sampling day on RMSSD during periods 2 and 3 (Table 7). There was a strong correlation between HR and RMSSD over the experimental period, with RMSSD decreasing as $\mathrm{HR}$ increased $\left(R^{2}=\right.$ $0.75 ; P<0.001)$. 


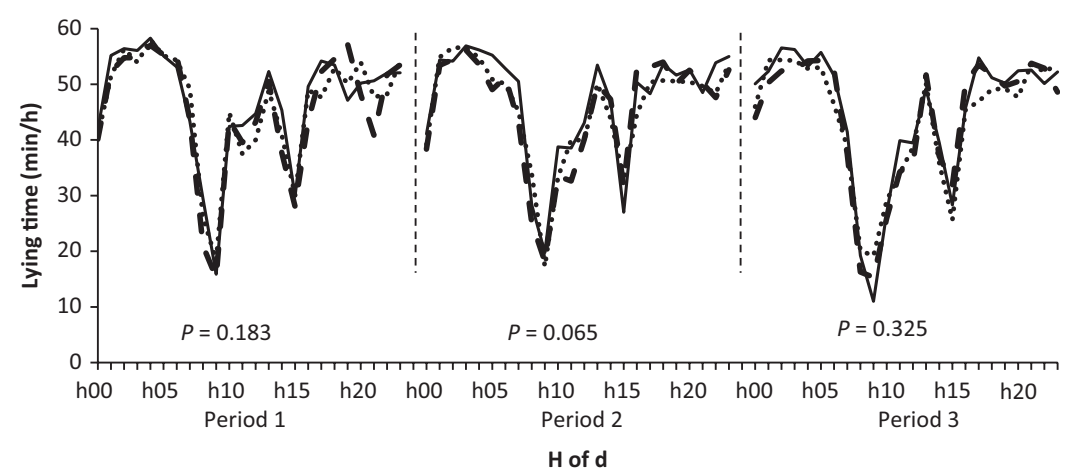

Figure 4. Hourly lying behaviour of calves over the milk step-down and weaning periods. OAD14 $(--)=$ once-a-day feeding milk replacer diet from $14 \mathrm{~d}$ of age, OAD28 $(-)=$ once-a-day feeding milk replacer diet from $28 \mathrm{~d}$ of age, TAD $(\cdots \cdots)=$ twice-a-day feeding milk replacer diet.

Table 7: Average RMSSD ${ }^{1}(\mathrm{~ms})$ and $\mathrm{HR}^{2}$ (bpm) values of calves throughout Periods 1-3

\begin{tabular}{|c|c|c|c|c|c|c|c|}
\hline \multirow[t]{2}{*}{ Period $^{\mp}$} & \multirow[t]{2}{*}{ Variable } & \multicolumn{3}{|c|}{ Dietary treatment $(D)$} & \multirow[t]{2}{*}{ SED } & \multicolumn{2}{|c|}{$P$-value } \\
\hline & & OAD14 ${ }^{3}$ & OAD28 $^{3}$ & TAD $^{3}$ & & $D$ & $D \times T^{4}$ \\
\hline \multirow[t]{2}{*}{1} & RMSSD & 24.3 & 42.9 & 27.0 & 10.46 & 0.264 & 0.061 \\
\hline & $\mathrm{HR}$ (bpm) & 100.8 & 86.0 & 92.5 & 7.92 & 0.209 & 0.204 \\
\hline \multirow[t]{2}{*}{2} & RMSSD & 24.0 & 25.6 & 29.4 & 9.66 & 0.862 & 0.823 \\
\hline & $\mathrm{HR}(\mathrm{bpm})$ & 96.1 & 96.9 & 93.2 & 6.64 & 0.904 & 0.721 \\
\hline \multirow[t]{2}{*}{3} & RMSSD & 28.6 & 18.0 & 21.4 & 7.50 & 0.438 & 0.362 \\
\hline & $\mathrm{HR}(\mathrm{bpm})$ & 95.2 & 102.9 & 100.1 & 3.86 & 0.185 & 0.538 \\
\hline
\end{tabular}

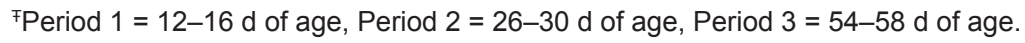

${ }^{1} \mathrm{RMSSD}=$ root mean square of successive differences.

${ }^{2} \mathrm{HR}=$ heart rate as measured in beats per minute $(\mathrm{bpm})$.

${ }^{3}$ Dietary treatment $(D)$ : OAD14 = once-a-day feeding milk replacer diet from $14 \mathrm{~d}$ of age, OAD28 = once-a-day feeding milk replacer diet from $28 \mathrm{~d}$ of age, TAD $=$ twice-a-day feeding milk replacer diet.

${ }^{4} T=$ sampling day, $D \times T=$ dietary treatment $\times$ sampling day interaction.

$\mathrm{SED}=$ standard error of the difference.

\section{Discussion}

\section{Intake and performance}

The neonatal rumen is underdeveloped, with calves relying primarily on milk or MR as a nutrient source for the first few weeks of life, only beginning to consume measurable amounts of solid feed at around 2 wk of age (Khan et al., 2008). Initiation of solid feed consumption stimulates metabolic and physical development of the rumen (Baldwin et al., 2004; Khan et al., 2011), with research indicating that provision of even a small amount of solid feed to veal calves results in demonstrable progression of forestomach development (Cozzi et al., 2002). An often-overlooked aspect of pre-wean calf feeding management is provision of drinking water. For example, Gottardo et al. (2002) reported that veal calves consumed more than $5 \mathrm{~L} / \mathrm{d}$ drinking water in addition to the average of approx. $14 \mathrm{~L} / \mathrm{d}$ of water given with MR. In the same study, calves offered drinking water and straw showed improved rumen papillae growth when compared with calves offered straw and no water. As highlighted by Kertz et al. (1984), sufficient quantities of water contained within milk cannot reach the rumen due to the oesophageal groove closure. Moisture is a limiting factor of gastrointestinal microbial growth in herbivores, meaning that provision of drinking water could help facilitate carbohydrate fermentation and volatile fatty acid (VFA) production; particularly when feeding a low digestible 
substrate, this stimulates rumen papillae development (Gottardo et al., 2002).

In the present study, OAD calves consumed approx. $500 \mathrm{~mL} / \mathrm{d}$ more drinking water than TAD calves during the pre-wean period. Jasper et al. (2008) and Budzynska \& Weary (2008) reported that calves offered warm water through the automatic milk feeding system for the first $2 \mathrm{~d}$ following weaning appeared to substitute milk with water. This resulted in a reduced behavioural response to weaning as indicated by fewer vocalisations when compared with abruptly weaned calves. As indicated by Allen (1996), satiety is partly mediated by gut fill, meaning that the warm water may have acted as a replacement for a proportion of the gut fill previously supplied by the milk feed and thus limited response to weaning. As such, the increased volume of drinking water consumed by OAD calves in the present study was likely a compensatory measure for reduced gut fill as a result of a lower daily MR volume. Burgstaller et al. (2017) reported that the average abomasal emptying time for $2 \mathrm{~L}$ of a milk protein-based $M R$ is between 3.2 and $3.4 \mathrm{~h}$. Although increasing MR concentration following the reduction of feeding frequency likely slowed abomasal emptying (Burgstaller et al., 2017), the increase in drinking water consumption in OAD calves could suggest that calves did not reach satiety. This was further compounded by the fact that total volume of water consumed, and therefore likely gut fill, remained below that of TAD calves. It must be considered therefore that feeding low levels of MR once daily represents a welfare concern. Future research should examine both volume and diurnal pattern of drinking water consumption relative to milk feeding frequency and volume as this may be a helpful indicator of calf hunger. Additionally, assessing the effects of MR concentration on abomasal emptying, particularly in once-daily feeding systems, is of importance as this could help to improve feeding management regimes and thus calf welfare.

In the present study, weaning weight and live-weight gain were comparable across treatments and similar to calves fed whole milk once or twice daily and weaned at $56 \mathrm{~d}$ of age as reported by Gleeson et al. (2007). FCE of young calves is approximately $50 \%$ (Bach \& Ahedo, 2008). Recent research has reported no differences in FCE in calves offered high (8 L/d) or low (4 L/d) levels of MR (De Paula et al., 2017) despite differences in DMI from concentrate feed. In the present study, FCE was $0.6 \mathrm{~kg}$ gain $/ \mathrm{kg}$ DMI across all treatments between days 5 and 55 , indicating that preweaning efficiency was not significantly impacted by feeding frequency. This suggests that if the quantity of MR as solids is the same and health status is high, as in the current study, calves receiving a reduced volume of MR in one feed per day can achieve comparable growth rates and feed efficiencies as those fed an increased volume twice per day. However, although there was no negative impact on calf performance, it must be remembered that affective state of calves was not measured within the parameters of this study. It is therefore possible that calves could have experienced hunger or disruption to behavioural needs as a result of the once-daily feeding regime imposed.

\section{Blood metabolites}

Concentration of BHBA has previously been indicated as a potential marker for starter feed consumption and rumen development in young calves (Quigley et al., 1991). The increasing concentrations of plasma BHBA up to the point of weaning in the present study were comparable to the pattern reported by Ferreira \& Bittar (2011) and followed the steady increase in concentrate intake. Following weaning, concentrate intake increased rapidly in calves across all treatments between days 56 and 59 resulting in increased BHBA concentration. Previous research reported increased BHBA concentration in gradually weaned calves (e.g. Khan et al., 2007) and was considered to be indicative of enhanced rumen function. In the present study, the tendency for increased BHBA in OAD calves compared with TAD calves at day 59 could therefore potentially indicate the start of earlier ruminal fermentation in these calves. Increased urea concentration in the post-wean period was also suggestive of increased ruminal fermentation of dietary protein as a result of enhanced solid feed intake following the withdrawal of MR (Quigley et al., 2006; Khan et al., 2007). The reduction in BHBA concentration observed across treatments at day 63 is likely as a result of rate of concentrate consumption becoming more stable (Quigley, 1996).

Glucose concentration was comparable to results reported by Ferreira \& Bittar (2011), with concentration declining as calf age increased. Lower glucose concentrations in TAD calves during Period 2 were likely due to the increased amount of dietary lactose received in the AM MR feed by OAD calves, with similar effects observed in calves fed on an elevated plane of MR (e.g. MacPherson et al., 2016). The increased glucose concentration in OAD calves during this period could also in some part be due to their increased concentrate consumption, resulting in an augmented DMI (Webb et al., 1969). The lower glucose concentration across all treatments post weaning was likely as a result of the shift from glucose to VFA as the main energy source and the establishment of ruminal function by the calf (Hammon et al., 2002).

Quigley (1996) reported a negative correlation between NEFA concentration and calf starter intake, which could explain the decrease in NEFA concentration in OAD14 calves during Period 2. Increase in NEFA concentration can be indicative of body fat mobilisation due to nutritional stress (Khan et al., 2007); however, no increases were observed following 
weaning. Therefore, it could be suggested that calves, regardless of milk feeding regime, were consuming sufficient concentrate to support physiological requirements (Ferreira \& Bittar, 2011). The combination of higher BHBA and urea concentration coupled with decreasing glucose and NEFA concentrations can be ascribed to the beginning of ruminal fermentation and thus the commencement of transition to functional ruminant (Khan et al., 2007).

\section{Behavioural and physiological measures}

Observational and acoustic monitoring techniques are often used to assess calf reaction to common husbandry practices; however, these methods can be time consuming and costly (Rushen et al., 2012). Increasingly, automatic monitoring technologies that allow the non-invasive collection of behavioural and physiological data are being employed on-farm (Sutherland et al., 2018). Previous research investigating the effects of feeding regime on calf behaviour have employed the use of automatic feeding systems, with increases in unrewarded visits to the feeder linked to calf hunger (Rosenberger et al., 2017). However, these are not applicable in systems where calves are individually penned. As such, investigating the use of monitoring technologies that can be used across housing systems is of great importance. Therefore, the main aim of this study was to use novel sensor technologies combined with traditional physiological measures as a means of further elucidating the impact of nutritional change on pre-weaned dairy calves.

\section{Haematological variables}

Acute-phase proteins such as $\mathrm{Hp}$ have been shown to change in concentration as a response to internal or external challenges caused by stress or infection (Murata et al., 2004). The increase in $\mathrm{Hp}$ concentration between 14 and $21 \mathrm{~d}$ of age in the present study was possibly as a result of calves receiving primary vaccination at 2 wk of age, which can result in an increase in symptoms of illness. The lack of measurable increase in $\mathrm{Hp}$ concentration as a result of reduction in milk feeding frequency at $28 \mathrm{~d}$ of age in the present study was comparable to that reported by Hulbert et al. (2011). Although there was no increase in $\mathrm{Hp}$ concentration following weaning, as was reported by Kim et al. (2011), the level observed in the present study could again be as a result of the effects of secondary vaccination. The lack of measurable response as a result of reduction in MR feeding frequency or weaning could suggest that these events did not evoke a physiological response measurable by $\mathrm{Hp}$ concentration alone.

\section{Infrared thermography}

IR thermography has been shown to be a viable method of detecting fluctuations in radiated temperature occurring as a result of physiological changes caused by external stressors
(Stewart et al., 2005). Calves did not elicit a measurable response in terms of IR eye temperature change as a result of reduction in milk feeding frequency from twice to once daily; however, IR temperature decreased in the period following weaning. Weaning is regarded as one of the most significant stressors in early life (Weary et al., 2008), and as such, this decrease could potentially indicate a more prolonged stress response to withdrawal of the milk feed. Previous research has indicated that mature cows undergoing periods of feed restriction display a reduction in heat production (Freetly et al., 2006); thus, it is also possible that the decrease in radiated temperature is an acute physiological response to the change in primary energy source as a result of the removal of the milk feed at weaning.

To the best of the authors' knowledge, neither the variation in the strength of relationship between age and temperature method nor the decrease in IR temperature following weaning has been reported in any other studies. Further research is required to examine effects of age on IR temperature and to investigate the relationship between IR temperature and core body temperature.

\section{Calf lying behaviour}

Calf response to common management practices such as limit feeding and weaning (Budzynska \& Weary, 2008; Jasper et al., 2008) has previously been assessed using measures of activity. De Paula Vieira et al. (2008) reported that calves fed restricted amounts of milk spent $1 \mathrm{~h}$ longer standing than those fed ad libitum milk, indicating that standing time could be used as a behavioural indicator of hunger. In the present study, there was no measurable difference in lying time throughout the pre-wean period between treatments. This could suggest either that reduction of feeding frequency did not evoke a measurable response or it could be that the individual housing system imposed restricted measures of activity. As such, studies in which the number of focal calves is increased or where calves are group housed could have different results. Studies comparing abrupt versus gradual weaning (e.g. Budzynska \& Weary, 2008) have reported an increase in activity in abruptly weaned calves following withdrawal of milk. The decrease in total daily lying time in TAD calves compared with that in OAD28 calves could suggest a behavioural response to weaning in TAD calves and was likely representative of increased time standing to consume concentrate. Concentrate intake was increased in OAD28 calves prior to weaning, and thus, the proportion of time spent standing did not increase at the same rate as TAD calves, potentially indicating that OAD28 calves were better able to adapt to the nutritional change imposed at weaning (Jasper et al., 2008). Calves in the present study were established on solid feed prior to weaning, consuming on average $1.3 \mathrm{~kg} \mathrm{DM}$ of concentrate on the day preceding 
withdrawal of MR; this potentially mitigates the behavioural response to weaning.

\section{Heart rate and heart rate variability}

Measures of HR and HRV have previously been used to examine physiological response to stressors in dairy cattle (Kovacs et al., 2014). Although HRV can be measured in several ways, RMSSD, a measurement based on the time between each heartbeat, is considered as one of the most informative methods (Clapp et al., 2014). This is because it is linked to vagal tone, which is a useful indicator of how an animal responds to stress (von Borell et al., 2007; Kovacs et al., 2014). Calves under internal or external stress have previously been reported as having an increased HR, decreased RMSSD and therefore lower vagal tone when compared to non-stressed calves (Mohr et al., 2002). It could be hypothesised, therefore, that imposing a reported nutritional stressor (Hulbert et al., 2011) such as reducing milk feeding frequency from twice to once daily would result in a demonstrable physiological response, in this instance, a decrease in RMSSD. Thus, the decrease in RMSSD values of OAD14 calves in Period 1 when compared that of OAD28 calves could potentially be indicative of a stress response to reduction in milk feeding frequency at $14 \mathrm{~d}$ of age. Clapp et al. (2014) reported increasing RMSSD values in the 5-d period following weaning, indicating that calves were becoming less stressed; however, in the current study, RMSSD values on the day of and following weaning were consistent to those found during the pre-wean period. This suggests that, in terms of HRV, calves reared according to the management strategies described did not elicit a measurable response to imposed nutritional stressors; being reduction of milk feeding frequency at $28 \mathrm{~d}$ of age and weaning. The results observed in OAD14 calves following the reduction in feeding frequency could indicate that imposing once-daily milk feeding at $14 \mathrm{~d}$ of age is potentially perceived as a stressor and requires further investigation.

\section{Conclusions}

Results from the current study suggest that providing individually housed calves with a low-to-moderate level of milk powder of $625 \mathrm{~g}$ in one meal per day from $28 \mathrm{~d}$ of age had limited effects on calf performance in the pre- and immediately post-wean period. Effects on behavioural and physiological measurements collected using the aggregate of novel, non-invasive monitoring technologies and haematological analysis described in this study were also limited. It must also be remembered, however, that calves may have been affected by reduction in feeding frequency in ways that were not investigated within the parameters of this study. It would be beneficial, therefore, for future research investigating the impact of management-imposed nutritional stressors to consider the inclusion of measures of affective state. Additionally, the health status of these calves was high; as such, similar results may not be obtained where incidence of morbidity is increased or where calves are group housed. The increase in volume of drinking water observed in calves fed MR once daily is likely suggestive of hunger, thus ensuring that calves established on solid feed prior to the introduction of a once-daily MR feeding system is of vital importance to calf welfare. The physiological changes observed in OAD14 calves following reduction in milk feeding frequency at $14 \mathrm{~d}$ of age, as indicated by a decrease in HRV and an increase in $\mathrm{Hp}$ concentration, require further investigation.

\section{Acknowledgements}

The authors gratefully acknowledge the assistance of Dr. Marijntje Speijers and the Agri-Food and Biosciences Institute, Hillsborough Research Technical staff: Barbara Waters, Andrew Brown, Bernard Lagan, Jennifer Meeke and Graham Finney. Many thanks are also due to the farm staff (Stanley Boville, John Ward and Colin Henry) for their assistance with calf management throughout the study.

\section{References}

Allen, M.S. 1996. Physical constraints on voluntary intake of forages by ruminants. Journal of Animal Science 74: 3063-3075.

Anonymous. 1996. Task force of the European society of cardiology the North American Society of Pacing Electrophysiology. Heart rate variability: standards of measurement, physiological interpretation, and clinical use. Circulation 93: 1043-1065.

Bach, A. and Ahedo, J. 2008. Record keeping and economics of dairy Heifers. Veterinary Clinics of North America: Food Animal Practice 24: 117-138.

Bach, A., Terre, M. and Pinto, A. 2013. Performance and health responses of dairy calves offered different milk replacer allowances. Journal of Dairy Science 96: 7790-7797.

Baldwin, R.L.V., Mcleod, K.R., Klotz, J.L. and Heitmann, R.N. 2004. Rumen development, intestinal growth and hepatic metabolism in the pre- and postweaning ruminant. Journal of Dairy Science 87: E55-E65.

Bayne, J.E., Walz, P.H., Passler, T., White, B.J., Theurer, M.E. and Van Santen, E. 2016. Use of three-dimensional accelerometers to evaluate behavioral changes in cattle experimentally infected with bovine viral diarrhea virus. American Journal of Veterinary Research 77: 589-596.

Bonk, S., Burfeind, O., Suthar, V.S. and Heuwieser, W. 2013. Technical note: evaluation of data loggers for measuring lying behavior in dairy calves. Journal of Dairy Science 96: 3265-3271. 
Borchers, M.R. and Bewley, J.M. 2015. An assessment of producer precision dairy farming technology use, prepurchase considerations, and usefulness. Journal of Dairy Science 98: 4198-4205.

Budzynska, M. and Weary, D.M. 2008. Weaning distress in dairy calves: Effects of alternative weaning procedures. Applied Animal Behaviour Science 112: 33-39.

Burgstaller, J., Wittek, T. and Smith, G.W. 2017. Invited review: abomasal emptying in calves and its potential influence on gastrointestinal disease. Journal of Dairy Science 100: 17-35.

Clapp, J.B., Croarkin, S., Dolphin, C. and Lyons, S.K. 2014. Heart rate variability: a biomarker of dairy calf welfare. Animal Production Science 55: 1289-1294.

Cozzi, G., Gottardo, F., Mattiello, S., Canali, E., Scanziani, E., Verga, M. and Andrighetto, I. 2002. The provision of solid feeds to veal calves: I. Growth performance, forestomach development and carcass and meat quality. Journal of Animal Science 80: 357-366.

Cushnahan, A. and Gordon, F. 1995. The effects of grass preservation on intake, apparent digestibility and rumen degradation characteristics. Animal Science 60: 429-438.

Davis, C.L. and Drackley, J.K. 1998. "The Development, Nutrition, and Management of the Young Calf". lowa State University Press, Ames, IA.

Dennis, T.S., Suarez-Mena, F.X., Hill, T.M., Quigley, J.D., Schlotterbeck, R.L. and Hulbert, L. 2018. Effect of milk replacer feeding rate, age at weaning, and method of reducing milk replacer to weaning on digestion, performance, rumination, and activity in dairy calves to 4 months of age. Journal of Dairy Science 101: 1-11.

De Paula, M.R., Oltramari, C.E., Silva, J.T., Gallo, M.P.C., Mourão, G.B. and Bittar, C.M.M. 2017. Intensive liquid feeding of dairy calves with a medium crude protein milk replacer: effects on performance, rumen, and blood parameters. Journal of Dairy Science 100: 4448-4456.

De Paula Vieira, A., Guesdon, V., De Passillé, A.M., Von Keyserlingk, M.A.G. and Weary, D.M. 2008. Behavioural indicators of hunger in dairy calves. Applied Animal Behaviour Science 109: 180-189.

Ferreira, L.S. and Bittar, C.M.M. 2011. Performance and plasma metabolites of dairy calves fed starter containing sodium butyrate, calcium propionate or sodium monensin. Animal 5: 239-245.

Finney, G., Gordon, A., Scoley, G. and Morrison, S. 2018. Validating the IceRobotics IceQube activity sensor for measuring lying behaviour in dairy calves. Livestock Science 214: 83-87.

Freetly, H.C., Nienaber, J.A. and Brown-Brandl, T. 2006. Changes in heat production by mature cows after changes in feeding level. Journal of Animal Science 84: 1429-1438.

Gleeson, D.E., O'Brien, B. and Fallon, R.J. 2007. Feeding of cold whole milk once daily to calves in a group and its effect on calf performance, health, and labour input. International Journal of Applied Research in Veterinary Medicine 5: 97-104.

Gottardo, F., Mattiello, S., Cozzi, G., Canali, E., Scanziani, E., Ravarotto, L., Ferrante, V., Verga, M. and Andrighetto, I. 2002. The provision of drinking water to veal calves for welfare purposes. Journal of Animal Science 80: 2362-2372.

Hammon, H.M., Schiessler, G., Nussbaum, A. and Blum, J.W. 2002. Feed intake patterns, growth performance, and metabolic and endocrine traits in calves fed unlimited amounts of colostrum and milk by automate, starting in the neonatal period. Journal of Dairy Science 85: 3352-3362.

Hulbert, L.E., Cobb, C.J., Carroll, J.A. and Ballou, M.A. 2011. Effects of changing milk replacer feedings from twice to once daily on Holstein calf innate immune responses before and after weaning. Journal of Dairy Science 94: 2557-2565.

Jasper, J., Budzynska, M. and Weary, D.M. 2008. Weaning distress in dairy calves: acute behavioural responses by limit-fed calves. Applied Animal Behaviour Science 110: 136-143.

Johnson, K.F., Chancellor, N., Burn, C.C. and Wathes, D.C. 2017. Analysis of pre-weaning feeding policies and other risk factors influencing growth rates in calves on 11 commercial dairy farms. Animal 12: 1413-1423.

Kaufmann, T., Sütterlin, S., Schulz, S.M. and Vögele, C. 2011. ARTiiFACT: a tool for heart rate artifact processing and heart rate variability analysis. Behavior Research Methods 43: 1161-1170.

Kehoe, S.I., Dechow, C.D. and Heinrichs, A.J. 2007. Effects of weaning age and milk feeding frequency on dairy calf growth, health and rumen parameters. Livestock Science 110: 267-272.

Kertz, A.F., Reutzel, L.F. and Mahoney, J.H. 1984. Ad-libitum water intake by neonatal calves and its relationship to calf starter intake, weight gain, feces score and season. Journal of Dairy Science 67 : 2964-2969.

Khan, M.A., Lee, H.J., Lee, W.S., Kim, H.S., Ki, K.S., Hur, T.Y., Suh, G.H., Kang, S.J. and Choi, Y.J. 2007. Structural growth, rumen development, and metabolic and immune responses of Holstein male calves fed milk through step-down and conventional methods. Journal of Dairy Science 90: 3376-3387.

Khan, M.A., Lee, H.J., Lee, W.S., Kim, H.S., Kim, S.B., Park, S.B., Baek, K.S., Ha, J.K. and Choi, Y.J. 2008. Starch source evaluation in calf starter: II. Ruminal parameters, rumen development, nutrient digestibilities, and nitrogen utilization in Holstein calves. Journal of Dairy Science 91: 1140-1149.

Khan, M.A., Weary, D.M. and Von Keyserlingk, M.A.G. 2011. Invited review: effects of milk ration on solid feed intake, weaning, and performance in dairy heifers. Journal of Dairy Science 94: 1071-1081.

Kienitz, M.J., Heins, B.J. and Chester-Jones, H. 2017. Growth, behavior, and economics of group-fed dairy calves fed once or twice daily in an organic production system. Journal of Dairy Science 100: 3318-3325.

Kim, M.H., Yang, J.Y., Upadhaya, S.D., Lee, H.J., Yun, C.H. and Ha, J.K. 2011. The stress of weaning influences serum levels of acutephase proteins, iron-binding proteins, inflammatory cytokines, cortisol, and leukocyte subsets in Holstein calves. Journal of Veterinary Science 12: 151-157. 
Kovacs, L., Jurkovich, V., Bakony, M., Szenci, O., Poti, P. and Tozser, J. 2014. Welfare implication of measuring heart rate and heart rate variability in dairy cattle: literature review and conclusions for future research. Animal 8: 316-330.

MacPherson, J.A.R., Berends, H., Leal, L.N., Cant, J.P., MartinTereso, J. and Steele, M.A. 2016. Effect of plane of milk replacer intake and age on glucose and insulin kinetics and abomasal emptying in female Holstein Friesian dairy calves fed twice daily. Journal of Dairy Science 99: 8007-8017.

Mohr, E., Langbein, J. and Nurnberg, G. 2002. Heart rate variability a noninvasive approach to measure stress in calves and cows. Physiology \& Behavior 75: 251-259.

Murata, H., Shimada, N. and Yoshioka, M. 2004. Current research on acute phase proteins in veterinary diagnosis: an overview. The Veterinary Journal 168: 28-40.

Porter, M. 1992. Comparison of sample preparation methods for the determination of the gross energy concentration of fresh silage. Animal Feed Science and Technology 37: 201-208.

Quigley, J.D. 1996. Influence of weaning method on growth, intake, and selected blood metabolites in Jersey calves. Journal of Dairy Science 79: 2255-2260.

Quigley, J.D., Caldwell, L.A., Sinks, G.D. and Heitmann, R.N. 1991. Changes in blood glucose, nonesterified fatty acids, and ketones in response to weaning and feed intake in young calves. Journal of Dairy Science 74: 250-257.

Quigley, J.D., Wolfe, T.A. and Elsasser, T.H. 2006. Effects of additional milk replacer feeding on calf health, growth, and selected blood metabolites in calves. Journal of Dairy Science 89: 207-216.

Raeth-Knight, M., Chester-Jones, H., Hayes, S., Linn, J., Larson, R., Ziegler, D., Ziegler, B. and Broadwater, N. 2009. Impact of conventional or intensive milk replacer programs on Holstein heifer performance through six months of age and during first lactation. Journal of Dairy Science 92: 799-809.

Rosenberger, K., Costa, J.H.C., Neave, H.W., Von Keyserlingk, M.A.G. and Weary, D.M. 2017. The effect of milk allowance on behavior and weight gains in dairy calves. Journal of Dairy Science 100: 504-512.

Rushen, J., Chapinal, N. and De Passille, A.M. 2012. Automated monitoring of behavioural-based animal welfare indicators. Animal Welfare 21: 339-350.

Soberon, F., Raffrenato, E., Everett, R.W. and Van Amburgh, M.E. 2012. Preweaning milk replacer intake and effects on long- term productivity of dairy calves. Journal of Dairy Science 95: 783-793.

Steen, R. 1989. A comparison of soya-bean, sunflower and fish meals as protein supplements for yearling cattle offered grass silagebased diets. Animal Production 48: 81-89.

Stewart, M., Webster, J.R., Schaefer, A.L., Cook, N.J. and Scott, S.L. 2005. Infrared thermography as a non-invasive tool to study animal welfare. Animal Welfare 14: 319-325.

Stewart, M., Webster, J.R., Verkerk, G.A., Schaefer, A.L., Colyn, J.J. and Stafford, K.J. 2007. Non-invasive measurement of stress in dairy cows using infrared thermography. Physiology \& Behavior 92: 520-525.

Stewart, M., Stookey, J.M., Stafford, K.J., Tucker, C.B., Rogers, A.R., Dowling, S.K., Verkerk, G.A., Schaefer, A.L. and Webster, J.R. 2009. Effects of local anesthetic and a nonsteroidal antiinflammatory drug on pain responses of dairy calves to hotiron dehorning. Journal of Dairy Science 92: 1512-1519.

Sutherland, M.A., Lowe, G.L., Huddart, F.J., Waas, J.R. and Stewart, M. 2018. Measurement of dairy calf behavior prior to onset of clinical disease and in response to disbudding using automated calf feeders and accelerometers. Journal of Dairy Science 101: 8208-8216.

Theurer, M.E., Amrine, D.E. and White, B.J. 2013. Remote noninvasive assessment of pain and health status in cattle. Veterinary Clinics of North America-Food Animal Practice 29: 59-74.

USDA. 2016. "Dairy 2014: Dairy Cattle Management Practices in the United States". United States Department of Agriculture-Animal and Plant Health Inspection Service (APHIS)-Veterinary Services (VS)-Center for Epidemiology and Health (CEAH), Fort Collins, CO.

Van Der Burgt, G. and Hepple, S. 2013. Legal position on 'once a day' feeding of artificial milk to calves. Veterinary Record 172: 135. von Borell, E., Langbein, J., Despres, G., Hansen, S., Leterrier, C., Marchant-Forde, J., Marchant-Forde, R., Minero, M., Mohr, E., Prunier, A., Valance, D. and Veissier, I. 2007. Heart rate variability as a measure of autonomic regulation of cardiac activity for assessing stress and welfare in farm animals - a review. Physiology \& Behavior 92: 293-316.

Weary, D.M., Jasper, J. and Hötzel, M.J. 2008. Understanding weaning distress. Applied Animal Behaviour Science 110: 24-41.

Webb, D.W., Head, H.H. and Wilcox, C.J. 1969. Effect of age and diet on fasting blood and plasma glucose levels, plasma nonesterified fatty acid levels, and glucose tolerance in dairy calves. Journal of Dairy Science 52: 2007-2013. 